\title{
Evaluation of the performance of light traps for sampling fish larvae in inshore temperate waters
}

\author{
Michael J. H. Hickford*, David R. Schiel \\ Marine Ecology Research Group, Department of Zoology, University of Canterbury, Private Bag 4800, Christchurch, New Zealand
}

\begin{abstract}
We compared 2 methods of collecting fish larvae in inshore temperate waters near the Kaikoura Peninsula, New Zealand: night collection with light traps and with a plankton net. The sampling design incorporated seasons (summer and autumn), moon phases (full and new) and habitats (reef and beach). The 2 methods were simultaneously deployed over 2 nights in replicates of 3 within each factor. The resulting 96 samples captured 8086 larvae from 14 families. The plankton net captured twice as many taxa from twice as many families as the light traps. No taxa were caught exclusively by the light traps. For all taxa, the fish larvae collected by the light traps were larger than those in the plankton net samples. Most taxa were more abundant in the summer and new moon samples taken by both methods. The 2 methods indicated different abundance patterns between habitats for most taxa. The light traps collected more of most taxa in the reef habitat, while the plankton net collected more in the beach habitat. The light trap samples complemented those taken by the plankton net. Both sampling methods could be combined in a sampling procedure to provide a more comprehensive picture of inshore ich thyoplankton assemblages.
\end{abstract}

KEY WORDS: Fish larvae $\cdot$ Light traps $\cdot$ Rocky reef $\cdot$ Sampling methods $\cdot$ New Zealand

\section{INTRODUCTION}

Because the successful completion of the pelagic phase of marine teleost fishes is crucial to subsequent fish populations, there has been considerable research on ichthyoplankton and the processes influencing survival and settlement of fish larvae from the open water community. A large portion of this work involves sampling and development of appropriate techniques to determine species composition and size classes of the ichthyoplankton in different environments. Although methods and equipment for sampling ichthyoplankton in open water are well developed, usually involving towing multiple plankton nets from large research vessels, most are not practicable for sampling in shallow inshore waters, particularly near rocky reefs. Many methods have been used for sampling ichthyoplankton close to reefs, including diver-guided plankton nets (Brogan 1994), moored nets (Kingsford \& Finn 1997), purse seines (Kingsford \& Choat 1985),

•E-mail: mike@zool.canterbury.ac.nz plankton pumps (Powlik et al. 1991), visual censuses (Kingsford \& Choat 1989), aggregation devices that attract fish into collection sites (Victor 1991) and light traps (Doherty 1987). However, it is clear that different methods usually sample different components of the ichthyoplankton, and the usefulness of each method is related to environmental conditions or types of habitat.

Light traps are useful passive devices for sampling larval fishes in marine habitats and have been instrumental in understanding larval abundance patterns along the Great Barrier Reef (Milicich \& Doherty 1994 , Thorrold \& Williams 1996). However, only 2 studies, both done in the tropics, have compared the performance of light traps with plankton nets, which are extensively used for sampling ichthyoplankton in marine waters. Light traps have rarely been used in temperate areas, and it is not known how useful they are in sampling the larval fish community in these less diverse regions. For example, the cold, murky waters of southern New Zealand support only ca 70 species of coastal fishes while the Great Barrier Reef supports more than 1500 fish species. Both the lower diversity 
and poorer water clarity of temperate waters are likely to affect the sampling properties of light traps and may limit their usefulness in these areas.

Light traps exploit the positive phototactic response of larval and juvenile fishes. Therefore, their success depends on the ability of larvae to see a light, to swim towards it and enter an illuminated enclosure (Brogan 1994), all of which may change during ontogeny (Bulkowski \& Meade 1983) or with light intensity and wavelength (Gehrke 1994). It is generally accepted that light traps are both species-and size-selective (Gregory \& Powles 1985, 1988, Doherty 1987, Thorrold 1992, 1993, Choat et al. 1993, Brogan 1994) and, therefore, it is necessary to determine the sampling properties of light traps before incorporating them into a sampling design.

The purpose of our study was to compare light traps and plankton ncts for sampling the inshore larval fish community. Our general question was whether these 2 methods yielded the same taxonomic composition, relative abundance of taxa and size-frequency of fish larvae. Because the ichthyoplankton can vary seasonally, with the phase of the moon and by habitat, we incorporated these as factors in our sampling design. We, therefore, posed as null hypotheses that the light trap and plankton net samples would be identical in 2 inshore habitats, 2 seasons and 2 moon phases.

\section{METHODS}

Study area. Sampling was done at 2 sites on the southern side of the Kaikoura Peninsula, on the east coast of the South Island, New Zealand (Fig 1). The first site (reef habitat) had a rocky reef substrate with dense beds of macroalgae (predominately Marginariella boryana and Carpophyllum maschalocarpum) and a mean depth of $4.2 \mathrm{~m}$. It was interspersed with deep channels (maximum depth $9 \mathrm{~m}$ ) and rocky pinnacles. The second site (beach habitat) was adjacent to a fine shingle beach (5 to $10 \mathrm{~mm}$ particle diameter), was free of macroalgae and was situated over a gently sloping sandy substrate. It had a mean depth of $4.5 \mathrm{~m}$ and a maximum depth of $8 \mathrm{~m}$. The nearest rocky reef was ca $300 \mathrm{~m}$ alongshore. The 2 sites were separated by rocky promontories and a distance of $1.6 \mathrm{~km}$.

Sampling gear. We constructed light traps that were a modified version of those described by Doherty (1987). The body of the light trap (Fig. 2) was made from a 240 I mobile plastic waste bin (Sulo, Australia), divided by 2 opaque partitions into 3 chambers. Three sides of the upper chamber were fitted with clear plastic windows $(290 \times 190 \mathrm{~mm})$, each containing 2 moulded entrance slots. Each horizontal slot tapered from $60 \times 300 \mathrm{~mm}$ down to $12 \times 250 \mathrm{~mm}$. The partitions

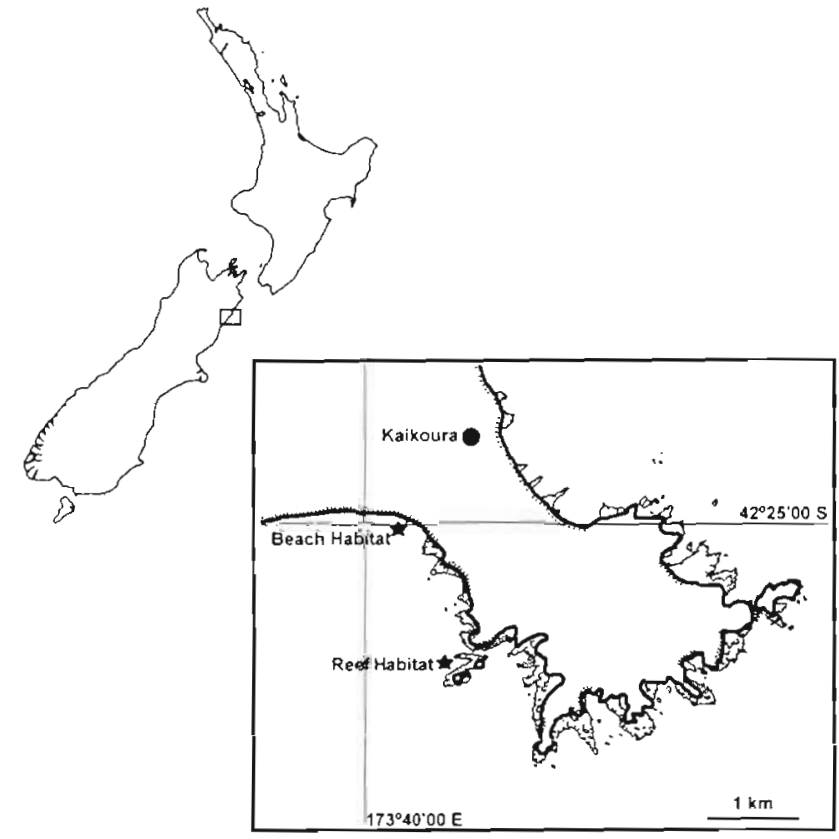

Fig. 1. Kaikoura Peninsula, New Zealand, showing position of beacr and reef habiai sampling sites

separating the chambers contained 2 identical slots. The middle chamber had no external entrance slots but was fitted with a $250 \times 300 \mathrm{~mm}$ clear plastic window. The lower chamber was fitted with $0.5 \mathrm{~mm}$ stainless steel mesh panels ( $240 \times 150 \mathrm{~mm})$ on 3 sides and a $50 \mathrm{~mm}$ drain hole (closed with a rubber stopper).

A central waterproof core ran through all 3 chambers. The upper section of the core was constructed from $150 \mathrm{~mm}$ wastepipe and contained a rechargeable lead-acid battery (12 V, $10 \mathrm{Ah}$ ) and a digital timing mechanism. The lower section of the core was constructed of $40 \mathrm{~mm}$ clear plastic tube and contained the 3 light sources ( $6 \mathrm{~W}$ fluorescent tubes). Each of the light sources was contained solely within a chamber. The timer mechanism was identical to that described by Doherty (1987), with the light in the lower chamber remaining lit throughout the sampling sequence and the lights in the upper and middle chambers alternating at 5 min intervals.

The plankton net had a $707 \times 707 \mathrm{~mm}$ mouth $\left(0.5 \mathrm{~m}^{2}\right)$ and was constructed from $280 \mu \mathrm{m}$ mesh. The net was a box-pyramid design with a filtration efficiency of $1: 12$. A General Oceanics digital flowmeter (Model 2030R) was fitted in the mouth of the net (at 0.33 of the net width) to determine the volume of water filtered per tow. The net was towed with a 4 -point bridle alongside a $6 \mathrm{~m}$ boat. The net was rigged so that it sampled with the uppermost edge of the mouth of the net at a fixed depth of $1 \mathrm{~m}$ and was towed for 5 min at a speed of ca $1 \mathrm{~m} \mathrm{~s}^{-1}$ 


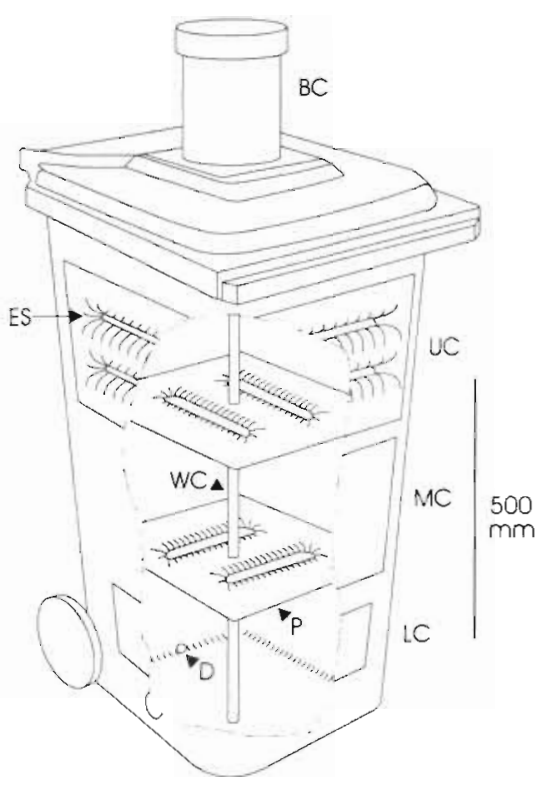

Fig. 2. Diagram of a light trap with the side partially cut away (BC: battery chamber; UC: upper chamber; MC: middle chamber; LC: lower chamber; P: partition; D: drain; WC: waterproof core; ES: entrance slot)

Sampling procedure. The reef and beach habitats were sampled on 2 nights during both a new moon (30 January 1997 and 3 February 1997) and a full moon (17 February 1997 and 21 March 1997) in summer. This sampling design was repeated during a new moon (31 March 1997 and 2 April 1997) and a full moon (15 April 1997 and 17 April 1997) in autumn. On each night, the 2 different sampling methods were deployed in both habitats. The 2 habitats were sampled in random order using the following method: 2 h after dusk, 3 automated light traps were deployed. Each light trap was suspended below an anchored buoy so that the entrance slots into the light trap were $1.5 \mathrm{~m}$ below the surface. The light traps were positioned ca $15 \mathrm{~m}$ apart. The 3 light traps were programmed to start simultaneously, sample for $30 \mathrm{~min}$ and then shut down. The light traps were left in the water for no more than $1 \mathrm{~h}$ in total. While the light traps were sampling, 3 replicate tows were made nearby with the plankton net. All tows were completed approximately $100 \mathrm{~m}$ from the anchored light traps and filtered 138 to $218 \mathrm{~m}^{3}$ of water per tow.

After the completion of each sample, the plankton net and light traps were washed thoroughly with pumped seawater and the sample was fixed in buffered $10 \%$ formalin in seawater. All fish larvae were removed from the samples using a dissection microscope, identified to the lowest possible taxonomic level, and stored in buffered $2 \%$ formalin in freshwa- ter. All fish (except those that were badly damaged) were measured to the nearest $0.5 \mathrm{~mm}$ by placing them on a graduated slide. Notochord length was measured for preflexion and flexion larvae, and standard length was measured for postflexion larvae.

For light traps, abundance is given as the number of fish per sample. Plankton net samples were standardised to the number of fish per $200 \mathrm{~m}^{3}$.

Analysis. Two types of data were collected. Both the plankton net and light traps collected a wide range of species allowing tests of species richness between sampling procedures. Because all undamaged fish larvae were measured, sizes could be compared for fish captured by the 2 sampling methods across seasons, phases of the moon and habitat. Abundances of fish, comparing the 2 sampling methods and their interactions with other factors, could not be tested because the volume of water sampled by light traps for each species is unknown. However, a correlation coefficient was calculated for the abundance of each taxon in the samples from the 2 methods by summing the abundance of individual taxa across the 3 replicates on each sampling occasion and correlating this total with the total obtained from the other sampling method.

The size-frequency distributions of fish larvae caught by the plankton net and light traps were compared using the Kolmogorov-Smirnov (K-S) test. We tested the total fish sample and 7 individual taxa, which were selected on the basis of comprising at least $1 \%$ of the total catch in either sampling method.

To test the number of taxa caught between light traps and the plankton net across seasons, phases of the moon and habitat, a mixed model ANOVA was used with the factors method (light trap and plankton net), season (summer and autumn), moon phase (full and new), nights within season $x$ moon phase (treated as random) and habitat (reef and beach). Prior to ANOVA, the data were tested for homogeneity of variances using Cochran's test. Post hoc pooling was used to eliminate non-significant $(p>0.25)$ higher order interactions from the model (Underwood 1997).

\section{RESULTS}

In total, the 96 samples captured 8086 larval and pelagic juvenile fish from 14 families. There was a marked difference in the taxonomic composition of the samples taken by the 2 methods. The plankton net took almost twice as many taxa from twice as many families as the light traps (Table 1) and collected a wider size-range of individuals from most taxa. Overall, the light traps caught far fewer fish larvae than the plankton net (Table 1). However, all light trap and plankton net samples contained fish larvae. 
Table 1. Composition and size range of samples taken by plankton net and light trap. Data are pooled across season, moon phase and habitat. Summary of occurrences (Occ.), minimum (Min.), maximum (Max.) and mean ( $\bar{x}$ ) size (mm standard length), total number of individuals $(n)$ within each taxon and percentage $(" i)$ of total catch from 48 light trap samples and 48 plankton net samples

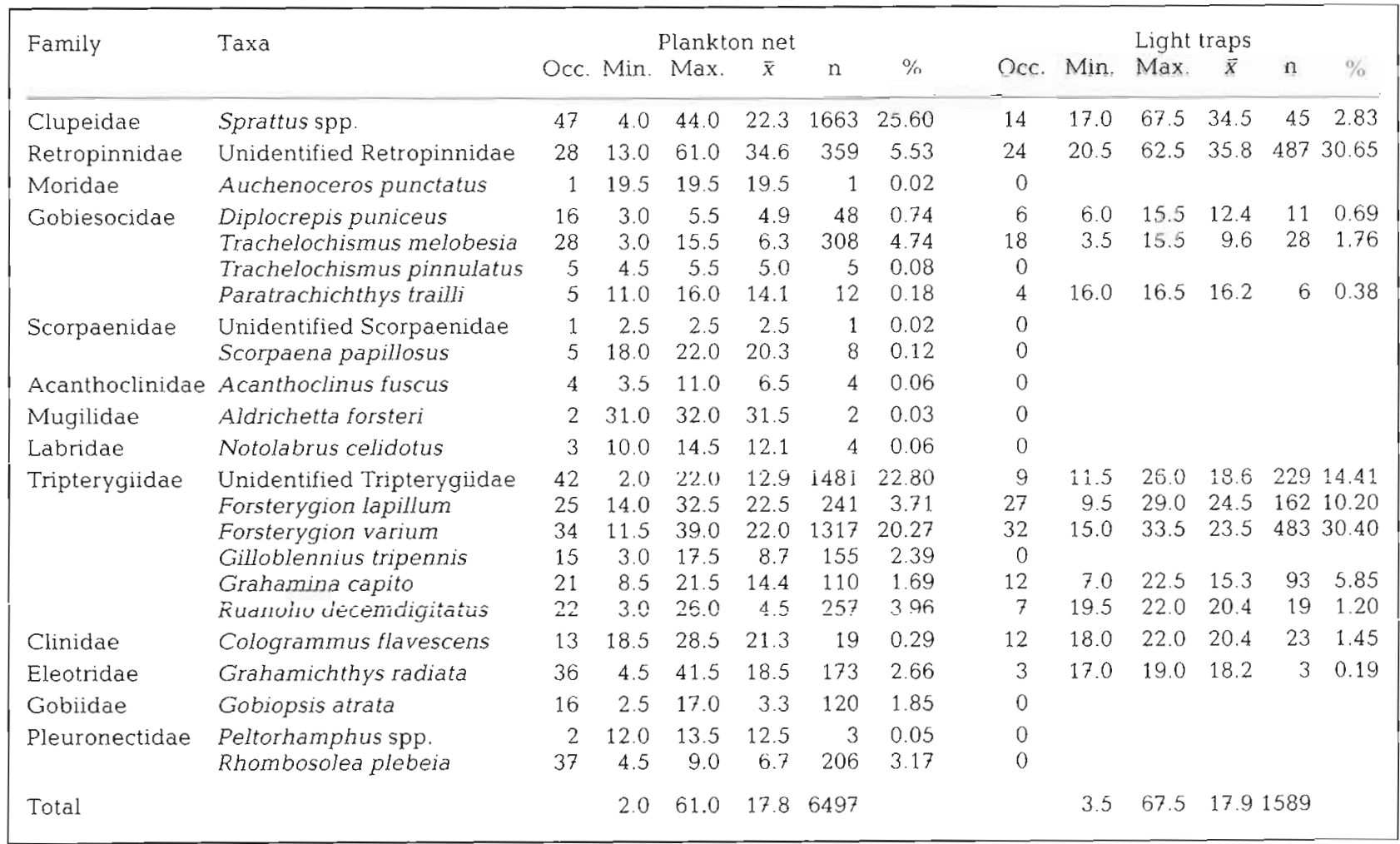

Eleven taxa occurred exclusively in the plankton net samples (Table 1), but no taxa were caught solely by the light traps. Eight of these 11 taxa were rare, each comprising $\leq 0.12 \%$ of the total plankton net catch. However, the remaining 3 taxa (Gilloblennius tripennis, Gobiopsis atrata and Rhombosolea plebeja) were relatively common in the plankton net samples, each occurring in at least 15 of the samples and having more than 100 larvae in total (Table 1 ).

There was little correlation between the abundance of each taxon in the plankton net and light trap samples. Only 6 (Sprattus spp., unidentified Retropinnidae, Trachelochismus melobesia, Paratrachichthys trailli, Grahamina capito, Ruanoho decemdigitatus) of the 23 taxa collected showed a positive correlation ( $p<0.05$ ) between the abundance of fish Iarvae in the plankton net and light trap samples. The remainder showed little correlation or were not collected by the light trap.

In both sampling methods, a few abundant taxa dominated the catch (Table 1). The 3 most abundant taxa collected by the plankton net and light traps accounted for 68.7 and $75.4 "$ " of the catch, respectively. The abundance distribution of the plankton net samples was more balanced than that of the light traps.
However, the rank of the taxa was very different between sampling methods. For example, Sprattus spp. was the most common taxon in the plankton net samples $(25.6 \%)$, but only the 6th most common in the light trap samples $(2.8 \%)$. Unidentified Retropinnidae was the most common group in the light trap samples $(30.7 \%)$, but only the 4 th most common in the plankton net samples $(5.5 \%)$.

There were significant differences between the mean standard length of fish captured by the 2 sampling methods in all taxa tested (Fig. 3). For all taxa, larvae collected by the light traps were significantly larger than those in the plankton net samples. The few Sprattus spp. captured by the light traps were on average $12 \mathrm{~mm}$ larger than those in the plankton net samples. The larger Sprattus spp. larvae caught by the light traps were missing from the samples taken by the plankton net (Fig. 3). The size-frequency distributions of retropinnids caught in the light traps and plankton net overlapped broadly, but there was a slight difference in the modal size class (Fig. 3). Only 5 of the retropinnids caught were $<20 \mathrm{~mm}$ standard length (SL), and the majority of fish larvae in samples collected by both methods were $>30 \mathrm{~mm}$ SL. When the 


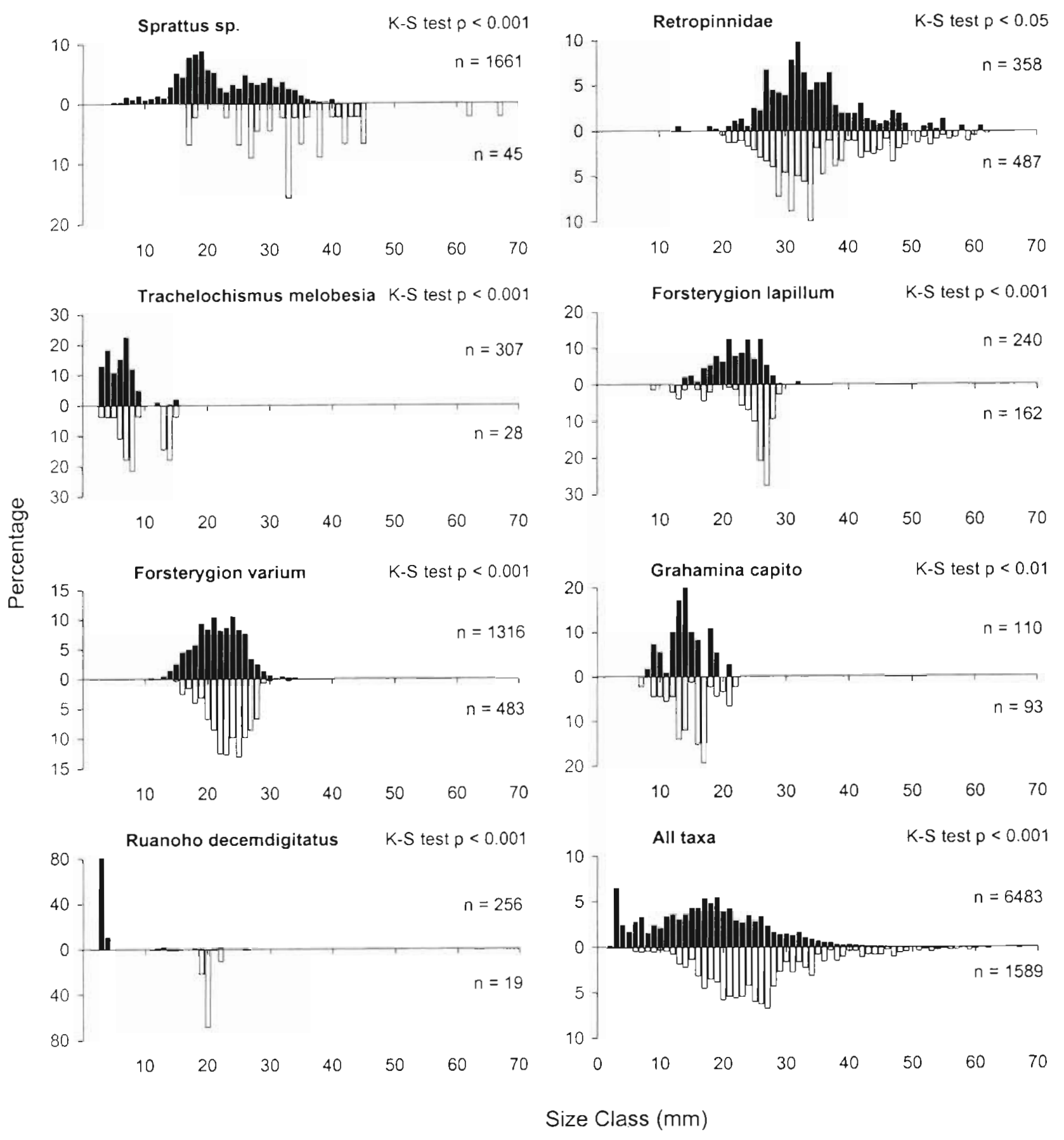

Fig. 3. Size distributions of fish larvae in plankton net samples (solid bars) and in light trap samples (open bars)

size-frequency of the total catch from the light traps is compared to that from the plankton net, it is clear that smaller individuals are more common in the plankton net (Fig. 3). Fish larvae $>40 \mathrm{~mm}$, which were relatively common in the light trap samples, were very rare in the plankton net samples.

The 3 taxa, Gilloblennius tripennis, Gobiopsis atrata and Rhombosolea plebeia, that were relatively com- mon in the plankton net samples but absent from the light trap samples had very few individuals in the larger size classes ( $>10 \mathrm{~mm}$ ) which comprised the majority of the light trap samples.

Most higher order interactions involving the factors method, season, moon phase and habitat were significant for the number of taxa caught (Table 2). The largest percentage of the model variation was ac- 
Table 2. ANOVA for total number of taxa in samples. Factors include method (plankton net and light trap), season (summer and autumn), moon phase (full and new), night ( 2 nights nested within season and moon phase) and habitat (reef and beach) ( $\%=$ percent of total variance accounted for by each factor)

\begin{tabular}{|llrrrr|}
\hline Source of variation & df & MS & $F$ & $p$ & $\%$ \\
\hline Method & 1,4 & 311.76 & 665.09 & 0.000 & 56.9 \\
Season & 1,4 & 58.59 & 152.03 & 0.000 & 10.7 \\
Moon & 1,4 & 14.26 & 37.00 & 0.000 & 2.6 \\
Night (S $\times$ Mn) & 4,70 & 0.39 & 0.76 & 0.558 & 0.3 \\
Habitat & 1,4 & 12.76 & 94.23 & 0.000 & 2.3 \\
Method $\times$ Season & 1,4 & 27.09 & 57.80 & 0.000 & 4.9 \\
Method $\times$ Moon & 1,4 & 0.84 & 1.80 & 0.251 & 0.2 \\
Season $\times$ Moon & 1,4 & 0.84 & 2.19 & 0.213 & 0.2 \\
Method $\times$ Night $(S \times$ Mn) & 4,70 & 0.47 & 0.92 & 0.459 & 0.3 \\
Method $\times$ Habitat & 1,4 & 31.51 & 104.31 & 0.000 & 5.8 \\
Season $\times$ Habitat & 1,4 & 11.34 & 83.77 & 0.000 & 2.1 \\
Moon $\times$ Habitat & 1,4 & 2.34 & 17.31 & 0.014 & 0.4 \\
Night (S $\times$ Mn) $\times$ Habitat & 4,70 & 0.14 & 0.27 & 0.899 & 0.1 \\
Method $\times$ Season $\times$ Moon & 1,70 & 2.34 & 5.00 & 0.028 & 0.4 \\
Method $\times$ Season $\times$ Habitat & 1,70 & 33.84 & 112.03 & 0.000 & 6.2 \\
Method $\times$ Moon $\times$ Habitat & 1,70 & 1.76 & 5.83 & 0.018 & 0.3 \\
Residual & 70 & 0.49 & 0.50 & 0.611 & 6.3 \\
\hline
\end{tabular}

The light traps and plankton net indicated very different abundance patterns between habitats for most common taxa. Most taxa, except Sprattus spp. and Ruanoho decemdigitatus, were more abundant in the plankton net samples from the beach habitat (Fig. 5). The light traps detected the opposite abundance patterns for most taxa; most of the common taxa, except Retropinnidae, were more common in the reef habitat (Fig. 5).

\section{DISCUSSION}

The taxonomic composition of larval fish in the samples was clearly dependent on the sampling method. The plankton net captured more taxa than the light traps, but many of these taxa were rare in the samples. All 12 taxa taken by the light traps were present in the plankton net sampies. Aithuugh the light traps sampled a subset of the taxa captured by the

counted for by the method of sampling (57\%). The night of sampling did not affect the number of taxa caught at any level. Overall, the plankton net caught an average of 5.8 taxa per sample while the light trap caught only 2.4 taxa per sample. The results are complicated, however, by the significant interactions involving season, habitat and moon phase. One major interaction (method $\times$ season $\times$ habitat), for example, resulted mainly because of the larger number of taxa caught in the plankton net in the beach habitat during summer (Fig. 4). The fewest taxa were caught by light traps during a full moon in autumn (Fig. 4). Overall, more taxa were caught during summer than in autumn, but the effect of moon phase depended on all the other major factors.

In the plankton net samples, the common taxa, except for the Retropinnidae, were more abundant in summer than in autumn (Fig. 5). Retropinnids were also more abundant in the light trap samples in autumn (Fig. 5). Two other taxa, unidentified Tripterygiidae and Forsterygion varium, were more abundant in the autumn light trap samples than in the summer samples.

Most of the common taxa were more abundant in the plankton net samples during a new moon than during a full moon (Fig. 5). The only exception to this was Rhombosolea plebeia, which was more abundant in the full moon samples. All taxa, with the exception of Cologrammus flavescens, were more abundant in the new moon light trap samples than in the full moon samples (Fig. 5). plankton net, the relative abundance of individual taxa in the 2 methods was only weakly correlated.

Differences in the relative abundance of individual taxa between samples taken by the 2 methods were usually associated with differences in size-frequency
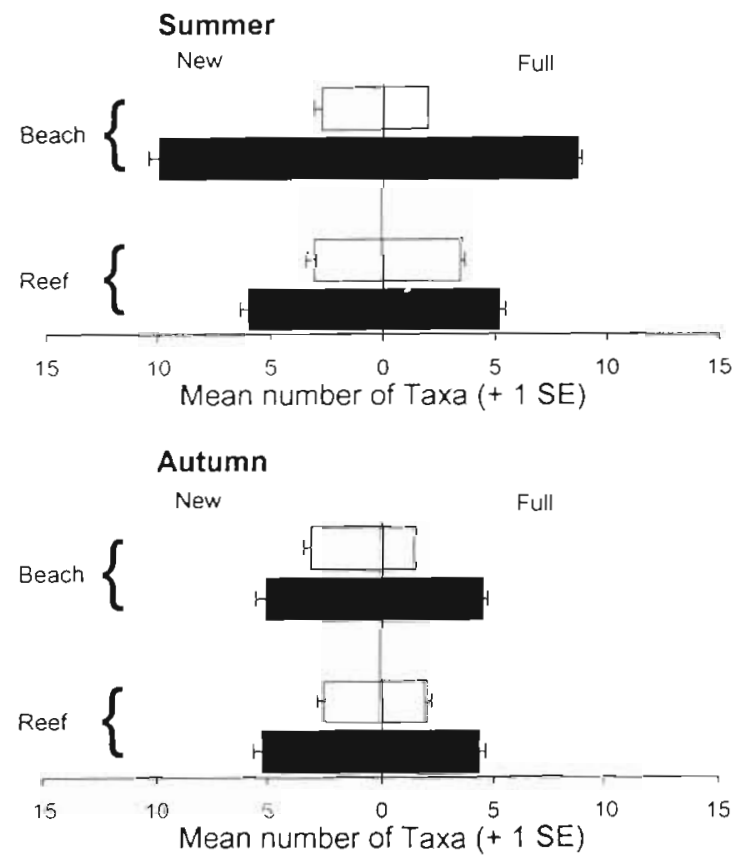

Fig. 4. Mean number of taxa (+1 SE) in samples collected in 2 seasons (summer and autumn) by 2 sampling methods (solid bars: plankton net; open bars: light trap) in 2 habitats (beach and reef) during 2 moon phases (new and full) 


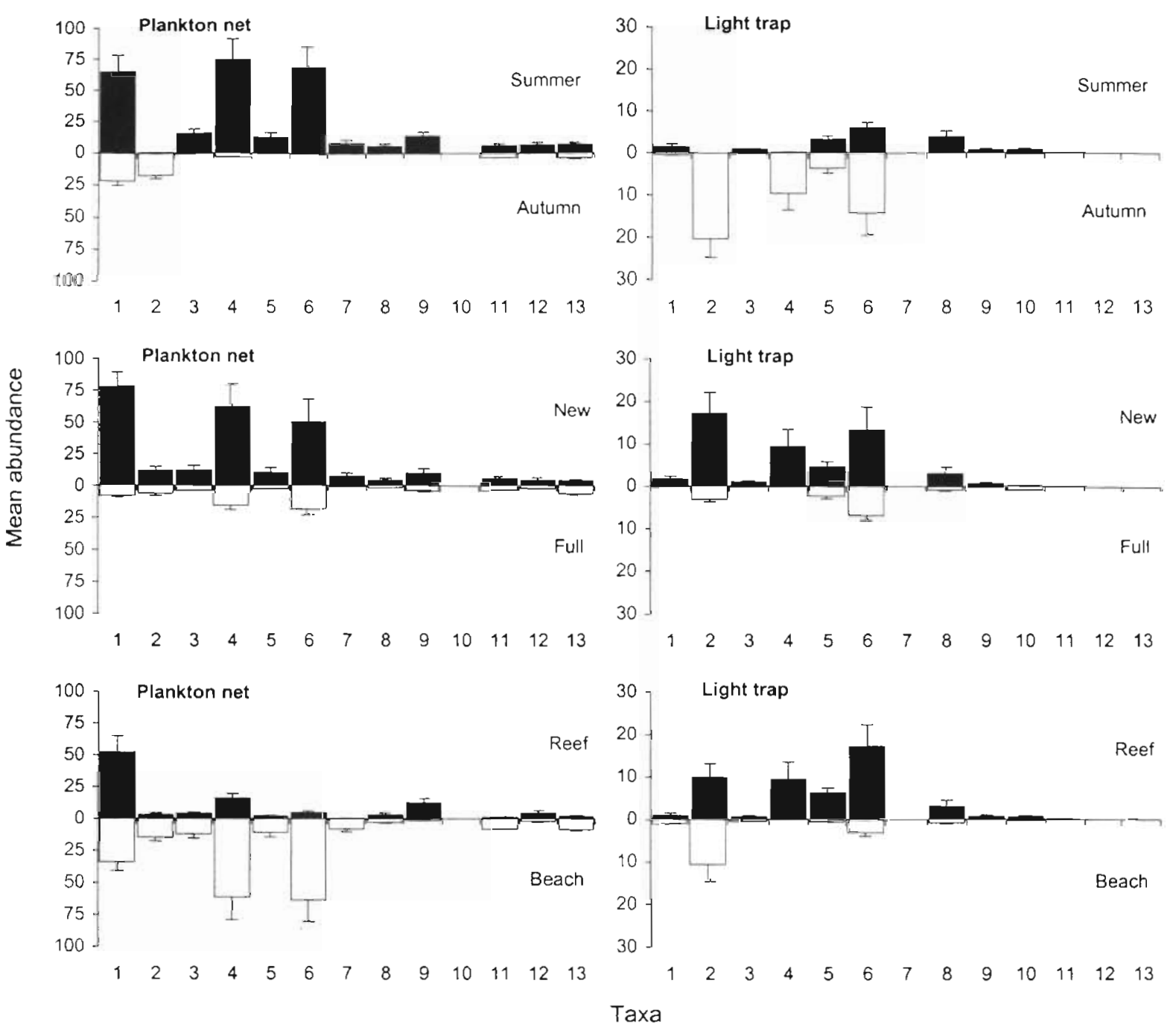

Fig. 5. Mean abundance $(+\mathrm{SE})$ of taxa collected by plankton net and light trap during 2 seasons, 2 phases of the moon and in 2 habitats (1. Sprattus spp.; 2: unidentified Retropinnidae; 3: Trachelochismus melobesia; 4: unidentified Tripterygiidae; 5: Forsterygion lapillum; 6: Forsterygion varium; 7: Gilloblennius tripennis; 8: Grahamina capito; 9; Ruanoho decemdigitatus; 10: Cologrammus flavescens; 11: Grahamichthys radiata; 12: Gobiopsis atrata; 13: Rhombosolea plebeia)

distributions. The mean size of fish larvae in light trap samples was greater than that of plankton net samples for all of the common taxa. Of all the taxa, retropinnids had the most similar size distributions between methods. This is likely to be a consequence of the relatively large size of all retropinnid larvae sampled. By $20 \mathrm{~mm}$ SL retropinnid larvae are strong swimmers (Stephens 1983) and easily capable of reaching the light trap. Our results suggest that larger pelagic stages are more likely to be attracted to and swim into a light trap than are small stages, which is similar to the findings of Choat et al. (1993) in tropical waters. As a result of this selectivity, taxa that are only represented by small individuals in the plankton are less likely to occur in light trap samples unless they have a strong swimming ability, a strong positive phototactic response, or both

In several cases, taxa that were abundant in the plankton net samples did not occur in the light trap samples (e.g. Gilloblennius tripennis, Gobiopsis atrata and Rhombosolea plebeia). This could be taken as evidence of these taxa not being positively phototactic. However, most of these fish were very small, and their absence from the light trap samples is likely to be a consequence of poor swimming ability. However, the light trap samples did contain very small individuals from 2 species of Gobiesocidae, suggesting that these species either possess a strong positive phototactic response during their early life, or are capable swimmers while still small, or a combination of both of these factors. 
Samples taken by plankton nets also can be selective, both in terms of their taxonomic composition and size distribution. By actively filtering fish larvae from a water mass, plankton net characteristics, such as towing speed (Nakamura 1992), mesh size (Somerton \& Kobayashi 1989) and mouth diameter (Thayer et al. 1983), interact with physical parameters such as light levels and water clarity (Brander \& Thompson 1989), as well as the behavioural response of the fish larvae themselves (Leak \& Houde 1987), to determine the composition and size structure of a sample. While small individuals may be under-represented in light trap samples, larger fish larvae are better able to avoid plankton nets (Brander \& Thompson 1989) and consequently may be under-represented in plankton tows. Net avoidance is lessened at night, either through reduced visual avoidance, or reduced activity levels (Brander \& Thompson 1989). Therefore, by using both methods at night, any differences in size distributions, due to net avoidance alone, should be decreased.

Little is known of the diel vertical distribution of larval fish in the study area. The vertical distribution of larval fish could affect the relative performance of the 2 sampling methods. It has been suggested that light traps may collect fish from the upper $5 \mathrm{~m}$ in tropical areas (P. J. Doherty unpubl., cited in Choat et al. 1993, Brogan 1994). This collection zone is likely to be less in our study area because of suspended matter in the water. However, our light traps appeared to illuminate the water within a radius of ca $3 \mathrm{~m}$, were anchored $1 \mathrm{~m}$ below the surface and, therefore, were likely to have sampled fish from the upper $4 \mathrm{~m}$ (i.e. most of the water column at the 2 study sites). Conversely, the plankton net sampled a relatively narrow depth stratum, with the mouth fixed at a depth of $1 \mathrm{~m}$. If any of the taxa present in the samples showed stratification in their vertical distribution, with a peak abundance outside the depth stratum sampled by the plankton net, it is likely that they would be under-represented in the samples. The extent of this bias between sampling methods is likely to vary with the depth of water at the sample site.

A major advantage of light traps over plankton nets is the ease with which light trap samples can be simultaneously replicated, by using multiple automated light traps. In deploying a plankton net, particularly in shallow rocky water with a small research boat, replicates can usually be obtained only by taking sequential tows. The time difference between replicate samples may result in increased inter-replicate variation. On most sampling accasions replicate light trap samples were less variable than the associated plankton tows. This reduced variance will make the light traps, when used in a structured design, more sensitive to detecting differences among treatment means.
Both sampling methods detected seasonal differences in the samples. Most taxa had a higher abundance in the summer samples. One exception to this was the retropinnids, which occurred almost exclusively in the autumn samples. Retropinnids are anadromous, with mature fish migrating during late summer and early autumn into freshwater to spawn (McDowall 1990). Consequently, retropinnid larvae are unlikely to appear in significant numbers in summer samples. The remaining taxa are predominately spring/early summer spawners (Ruck 1980, Ayling \& Cox 1987. Paulin \& Roberts 1992). The 2 sampling methods were generally in agreement with the patterns of seasonal abundance of individual taxa. Exceptions to this were unidentified Tripterygiidae, Forsterygion lapillum and Forsterygion varium which showed higher relative abundances in the autumn light trap samples. This may be a result of the size-selectivity of the light traps. During summer, tripterygiid larvae are common (as seen in the plankton net catch), but there are likely to be few large individuals for the light traps to attract. By autumn, the smaller individuals have grown to a size where they are more capabie swimmers and more easily attracted to the light traps. These larger individuals may not appear in the plankton net samples because they are close to settlement and consequently are found close to the substrate. For each of the 3 tripterygiid taxa, the larvae caught by the light traps in autumn were larger than those caught by the plankton net in summer (K-S test, $\mathrm{p}<0.001$ ). However, there was no significant difference between the sizes of larvae caught by the light traps in summer and autumn

Both sampling methods detected lunar differences in the samples. Most taxa had a higher abundance in samples collected during a new moon. While this pattern may be the result of a real difference in abundance between lunar phases, the efficiency of both sampling methods has been linked to light intensity. Avoidance of plankton nets is greater with increased light intensity (Thayer et al. 1983, Brander \& Thompson 1989), and the catch of light traps has been found to be negatively correlated with moon illumination (Gregory \& Powles 1985). Therefore, it would be expected that both sampling methods would capture fewer fish larvae during a full moon than during a new moon regardless of the relative abundance of the larvae during the different lunar phases.

The 2 sampling methods detected very different patterns of abundance between the 2 habitats. The light traps collected more of most taxa in the reef habitat, while the plankton net collected more in the beach habitat. An obvious reason for this discrepancy would be that smaller fish larvae were more abundant in the beach habitat and were captured by the plankton net, 
while larger larvae were more abundant in the reef habitat and captured by the light traps. However, further analysis of the size structure of the samples taken by the 2 methods did not show this pattern. There are several other possible reasons for this discrepancy. Suspended matter, disturbed by wave action at the beach site, meant that the water clarity at the beach site was worse than at the reef site. This may have reduced the radius inside which fish could detect and be attracted to the light trap. Consequently, the light trap catches would be greater in the clearer water over the rocky reef. Another possible reason for the discrepancy in patterns detected by the 2 sampling methods is that there may have been a difference in water current speed at the 2 sites. Doherty (1987) identified this factor as being of paramount importance when comparing samples taken with light traps at fixed locations. Sprattus spp. and retropinnid larvae, which were generally larger than other taxa and consequently stronger swimmers, may have been less affected by current speed and thus showed relatively equal abundances in the 2 habitats.

Our study shares 4 families (Clupeidae, Gobiesocidae, Tripterygiidae and Gobiidae) with Brogan's (1994), 1 of the 2 other studies comparing light traps and plankton nets. Brogan recorded little overlap in the size distribution of clupeids caught by the 2 sampling methods. The 2 size distributions for tripterygiids broadly overlapped, but the modal size classes differed markedly. Brogan (1994) attributed much of this variation to fish larvae avoiding daytime tows with small nets. Such avoidance, particularly by larger and therefore faster swimming fish larvae, has been demonstrated in several other studies (Clutter \& Anraku 1968 , Barkley 1972, Suthers \& Frank 1989). Both avoidance and diel vertical migration ensure that samples taken during daylight will not be equivalent to those taken at night (Leis 1991). In our study, both clupeid and individual tripterygiid species' size distributions overlapped broadly, but their means differed significantly. It is likely that by using both sampling methods at night the avoidance of plankton nets by larger fish was decreased.

Both previous studies comparing light traps and plankton nets in marine waters found that light traps collected fewer families than associated plankton tows. Brogan (1994) reported that his light traps collected 4 families that were not present in the plankton net samples. However, these families each accounted for a very small proportion $(\leq 0.03 \%$ ) of the total light trap catch. Neither our study nor Choat et al. (1993) recorded any families in light trap samples that were not present in plankton net samples.

Of the 19 large, inshore species whose adults were seen in extensive surveys of reefs around the Kaikoura
Peninsula (Hickford \& Schiel 1995), only 3 (Scorpaena papillosus, Aldrichetta forsteri and Notolabrus celidotus) were caught as larvae by either sampling method. These taxa were not abundant in the plankton samples collected. Larvae of Latridopsis ciliaris, Notolabrus fucicola and Odax pullus which, together with Notolabrus celidotus, dominate the inshore ichthyofauna were not found in our plankton samples. The reasons for the absence of these and other common species from the plankton samples are not clear, but probably involve a narrow depth distribution or extended offshore development. It is noteworthy that Kingsford \& Choat (1989) found very few larvae of common reef-dwelling fish in their plankton net samples in northern New Zealand.

In summary, the light traps used in this study attracted and captured only a subset of the taxa caught by the plankton net. The relative abundance of individual taxa in the light trap samples was very different to that in the plankton net samples. For all commonly occurring taxa the light traps collected significantly larger fish larvae than the plankton net. The light traps were as capable as the plankton net in detecting interseasonal and lunar phase differences in the abundance of fish larvae. Water clarity and current speed should be equivalent between sites to use light traps for comparative studies. In this study, the light trap samples complemented those taken by the plankton net. While the plankton net captured more small fish larvae and individuals from rare taxa, the light traps captured more large larvae which may have avoided the plankton net. Rather than choosing between the 2 methods, both can be usefully combined in a sampling programme to provide more comprehensive insight into the ichthyoplankton spectrum associated with nearshore rocky reefs

Acknowledgements. We thank Claus Bader, Chris Carter, Jo Davis and Craig Dolphin for assistance with field work. Dave Greenwood, Nick Etheridge, Franz Ditz and Claus Bader for help with designing and constructing the light traps and plankton net, Jack van Berkel for all manner of assistance, and the University of Canterbury for scholarship and research support. Comments by 4 anonymous reviewers were helpful in the development of this manuscript.

\section{LITERATURE CITED}

Ayling T, Cox GJ (1987) Collins' guide to the sea fishes of New Zealand. William Collins Publishers Ltd, Auckland

Barkley RA (1972) Selectivity of towed-net samplers. Fish Bull (Wash DC) 70:799-820

Brander K, Thompson AB (1989) Diel differences in avoidance of three vertical profile sampling gears by herring larvae. J Plankton Res 11:775-784

Brogan MW (1994) Two methods of sampling fish larvae over reefs: a comparison from the Gulf of California. Mar Biol $118: 33-44$ 
Bulkowski L, Meade JW (1983) Changes in phototaxis during early development of walleye. Trans Am Fish Soc 112: $445-447$

Choat JH, Doherty PJ, Kerrigan BA, Leis JM (1993) A comparison of towed nets, purse seine, and light-aggregation devices for sampling larvae and pelagic juveniles of coral reef fishes. Fish Bull (Wash DC) 91:195-209

Clutter RI, Anraku M (1968) Avoidance of samplers. In: Tranter DJ, Fraser AJ (eds) UNESCO monographs on oceanographic methodology. 2. Zooplankton sampling. UNESCO, Paris, p 57-76

Doherty PJ (1987) Light-traps: selective but useful devices for quantifying the distributions and abundances of larval fishes. Bull Mar Sci 41:423-431

Gehrke PC (1994) Influence of light intensity and wavelength on phototactic behaviour of larval silver perch Bidyanus bidyanus and golden perch Macquaria ambigua and the effectiveness of light traps. J Fish Biol 44:741-751

Gregory RS, Powles PM (1985) Chronology, distribution, and sizes of larval fish sampled by light traps in macrophytic Chemung Lake. Can J Zool 63:2569-2577

Gregory RS, Powles PM (1988) Relative selectivities of Miller high-speed samplers and light traps of collecting ichthyoplankton. Can J Fish Aquat Sci 45:993-998

Hickford MJH, Schiel DR (1995) Catch vs count: effects of gill-netting on reef fish populations in southern New Zealund. J Exp Mar Bicl Eco! 188:215-232

Kingsford MJ. Choat JH (1985) The fauna associated with drift algae captured with a plankton-mesh purse seine net. Limnol Oceanogr 30:61.8-630

Kingsford MJ, Choat JH (1989) Horizontal distribution patterns of presettlement reef fish: are they influenced by the proximity of reefs? Mar Biol 101:285-297

Kingsford MJ, Finn $M$ (1997) The influence of phase of the moon and physical processes on the input of presettlement fishes to coral reefs. J Fish Biol 51 (Suppl A):176-205

Leak JC, Houde ED (1987) Cohort growth and survival of bay anchory Anchoa mitchilli larvae in Biscayne Bay, Florida. Mar Ecol Prog Ser 37:109-122

Leis JM (1991) The pelagic stage of reef fishes: the larval biology of coral reef fishes. In: Sale PF (ed) The ecology of fishes on coral reefs. Academic Press Inc, San Diego, p $183-229$

MCDowall RM (1990) New Zealand freshwater fishes: a natural history and guide. Heinemann Reed, Auckland

Editorial responsibility: Otto Kinne (Editor),

Oldendorf/Luhe, Germany
Milicich MJ, Doherty PJ (1994) Larval supply of coral reef fish populations: magnitude and synchrony of replenishment to Lizard Island. Mar Ecol Prog Ser 110:121-134

Nakamura M (1992) Change of catch efficiency of a plankton net depending on towing speed. Bull Jpn Soc Sci Fish 58: $861-869$

Paulin CD, Roberts C (1992) The rockpool fishes of New Zealand. Southwestern Publishing Ltd, Auckland

Powlik JJ, St John MA, Blake RW (1991) A retrospective of plankton pumping systems, with notes on the comparative efficiency of towed nets. J Plankton Res 13:901-912

Ruck JG (1980) Early development of Forsterygion varium, Gilloblennius decemdigitatus, and G. tripennis (Pisces: Tripterygiidae). NZ J Mar Freshw Res 14:313-326

Somerton DA, Kobayashi DR (1989) A method for correcting catches of fish larvae for the size selection of plankton nets. Fish Bull (Wash DC) 87:447-455

Stephens RTT (1983) Native fish in the lake. In: Forsyth DJ, Howard-Williams C (eds) Lake Taupo: ecology of a New Zealand lake. PD Hasselberg, Wellington, p 111-118

Suthers IM, Frank KT (1989) Inter-annual distributions of larval and pelagic juvenile cod (Gadus morhua) in southwestern Nova Scotia determined with two different gear types. Can J Fish Aquat Sci 46:591-602

Thayer CW, Colby DR, Kjelson MA, Weinstein MP (1983) Estimates of larval-fish abundance: diurnal variation and influences of sampling gear and towing speed. Trans Am Fish Soc 112:272-279

Thorrold SR (1992) Evaluating the performance of light traps for sampling small fish and squid in open waters of the central Great Barrier Reef lagoon. Mar Ecol Prog Ser 89: $277-285$

Thorrold SR (1993) Post-larval and juvenile scombrids captured in light traps: preliminary results from the Great Barrier Reef lagoon. Bull Mar Sci 52:631-641

Thorrold SR, Williams DMCB (1996) Meso-scale distribution patterns of larval and pelagic juvenile fishes in the central Great Barrier Reef lagoon. Mar Ecol Prog Ser 145: $17-31$

Underwood AJ (1997) Experiments in ecology: their logical design and interpretation using analysis of variance. Cambridge University Press, Cambridge

Victor BC (1991) Settlement strategies and biogeography of reef fishes. In: Sale PF (ed) The ecology of fishes on coral reefs. Academic Press Inc, San Diego, p 231-260

Submitted: February 1, 1999; Accepted: April 29, 1999

Proofs received from author(s): September 13, 1999 